\title{
AUXOTYPES OF NEISSERIA GONORRHOEAE IN TORONTO: RELATIONSHIP TO PENICILLIN RESISTANCE AND TO SEX OF PATIENT
}

\begin{abstract}
Rosa SHTIBEL
Clinical Bacteriology Section, Laboratory Services Branch, Ontario Ministry of Health, P.O. Box 9000, Terminal 'A', Toronto, Ontario, M5W 1R5, Canada

SUmmary. The relationship of auxotype to penicillinase production, penicillin susceptibility, and sex of the patient, has been studied in 8446 non-penicillinase-producing and 153 penicillinase-producing Neisseria gonorrhoeae (PPNG) strains isolated during 1980-1983 in Toronto. Proline-requiring types constituted $51 \%$ of the PPNG and $13 \%$ of the non-PPNG strains; ornithine-requiring types constituted only $4 \%$ of the PPNG compared with $12 \%$ of the non-PPNG isolates. The various auxotypes of the non-PPNG isolates showed marked differences in their degree of resistance to penicillin; and the proportions of each auxotype from male and female patients were dissimilar.
\end{abstract}

\section{INTRODUCTION}

Changes in the nutritional requirements of Neisseria gonorrhoeae were reported by Carifo and Catlin (1973); and the unique requirements of some penicillin-susceptible strains were described by Knapp and Holmes (1975). The distribution of different auxotypes in parts of Canada has been reported from Hamilton, Ontario (Hendry and Stewart, 1979; Stewart and Hendry, 1979) and from Montreal, Quebec (Turgeon and Granger, 1980).

Thompson et al. (1978), in the USA, studied the relation between auxotype and the degree of resistance to antibacterial drugs. Pauze and Dillon (1982) recorded a steadily increasing proportion of penicillinase-producing $N$. gonorrhoeae (PPNG) among their gonococcal isolates. Shtibel (1982) reported the increasing incidence of penicillin-resistant non-PPNG cultures and their degree of resistance.

The purpose of this study was to survey the prevalence of different auxotypes of $N$. gonorrhoeae in Toronto, and to study their relationship to penicillinase-production, penicillin-susceptibility, and the sex of the patients from whom they were isolated.

\section{MATERIALS AND METHODS}

Cultures. During 1980-1983, 8599 isolates from anogenital and pharyngeal infections were confirmed in our laboratory as $N$. gonorrhoeae by the following criteria: Gram-negative diplococci; oxidase positive; production of acid from dextrose (but not maltose or saccharose with Cystine Trypticase Agar sugars (BBL); no growth on nutrient agar (Difco) at $22^{\circ} \mathrm{C}$; 
negative in o-nitrophenyl- $\beta$-D-galactopyranoside broth (Gibco); positive in the Difco Bacto-FA $N$. gonorrhoeae direct fluorescent antibody technique.

Penicillinase production was determined by the modified iodometric technique of Jorgensen et al. (1977). A good quality white bond starch paper was cut into square pieces $4 \times 4 \mathrm{~cm}$. These were soaked for $1 \mathrm{~min}$ in a solution of penicillin $\mathrm{G}(5 \mathrm{~g} / \mathrm{L})$, freshly prepared in monopotassium phosphate-sodium hydroxide buffer $0.05 \mathrm{M}, p \mathrm{H} \mathrm{7.0.} \mathrm{The} \mathrm{squares} \mathrm{were} \mathrm{used} \mathrm{immediately} \mathrm{or}$ stored frozen in polyethylene bags for up to 6 months.

A square was placed in the base of a 9-cm plastic petri dish, and inoculated with the test cultures, $1 \mathrm{~cm}$ apart, using a 2-mm platinum loop. A sheet of tissue paper was moistened with water and placed at the periphery of the petri dish to maintain a high level of humidity. The lid was replaced and the dish incubated, base down, for $15 \mathrm{~min}$ at $36^{\circ} \mathrm{C}$. The base of the dish, with the test paper still adherent, was then inverted over a jar of iodine crystals for a few seconds. Penicillinase production was indicated by a white halo around the inoculated area; with a negative result, the area around the inoculum was blue.

Penicillin susceptibility. The test medium consisted of GC Base (Difco) enriched with Isovitalex $0.1 \%$ and lysed horse blood $1.5 \%$ (Shtibel, 1975). A plate dilution method was used, with penicillin concentrations of $0 \cdot 12,0 \cdot 3,0 \cdot 6,1 \cdot 0,2 \cdot 0,3 \cdot 0$ and $6 \cdot 0 \mathrm{mg} / \mathrm{L}$. (For inoculation and incubation, see below-Auxotype determination.)

Auxotyping medium. A chemically defined medium was modified from that of Catlin (1973); the ingredients are shown in Table I.

The base solution (part 1) was divided into 83-ml portions. Amino-acids, vitamins and growth factors (part 2) were added to each portion, one or more of the amino-acids being omitted from some portions to test for dependency (see below). The medium was adjusted to $p \mathrm{H}$ $7 \cdot 2$ and sterilised by passage through a $0.22-\mu \mathrm{m}$ membrane filter (Millipore). Finally, the molten agar base (part 3) was added to each portion and the medium was poured into $100 \times 100 \times 15 \mathrm{~mm}$ square petri dishes (Falcon) $30 \mathrm{ml} / \mathrm{plate}$, and stored at $4^{\circ} \mathrm{C}$.

Auxotype determination. For each test, seven media were used: a positive control plate consisted of the complete auxotyping medium; a negative control plate lacked cystine and cysteine (usual growth requirements of $N$. gonorrhoeae); the other five plates lacked either proline, citrulline (testing the ability of ornithine present in the medium to replace a citrulline requirement), citrulline and ornithine (precursor amino acids in arginine synthesis), uracil, or hypoxanthine.

Bacteria were suspended in a buffered salt solution to the opacity of MacFarland nephelometric standard no.1, prepared by the addition of $0.1 \mathrm{ml}$ of $1 \%$ barium chloride to $9.9 \mathrm{ml}$ of $1 \%$ sulphuric acid. With a replicator, auxotyping plates were inoculated first, then the penicillin-susceptibility plates. Minimal inhibitory concentration (MIC) and nutritional requirements were determined after $48 \mathrm{~h}$ at $36^{\circ} \mathrm{C}$ in $\mathrm{CO}_{2} 5 \%$.

\section{RESULTS}

Of the 8599 isolates of $N$. gonorrhoeae, 153 were PPNG and 8446 were non-PPNG. Table II shows the relationship between penicillinase production and auxotype. Most of the PPNG isolates were either prototrophic (not requiring any of the amino-acids when each was omitted singly from the complete auxotyping medium) or proline requiring. The non-PPNG cultures had a wider range of nutritional requirements; in $2 \%$ of them, an unidentified requirement was revealed-they failed to grow on the complete auxotyping medium, although they grew well on the penicillin-susceptibility control medium.

Table III presents the distribution of penicillin susceptibility among the various auxotypes of non-PPNG. Of the $38 \%$ that were penicillin resistant (MIC $\geq 0.6 \mathrm{mg} / \mathrm{L}$ ), most were prototrophic or proline requiring. Moderate resistance (MIC $0.3 \mathrm{mg} / \mathrm{L}$ ) was found in $21 \%$, and most of these were proline-citrulline-uracil requiring. The 
TABLE I

Chemically defined medium

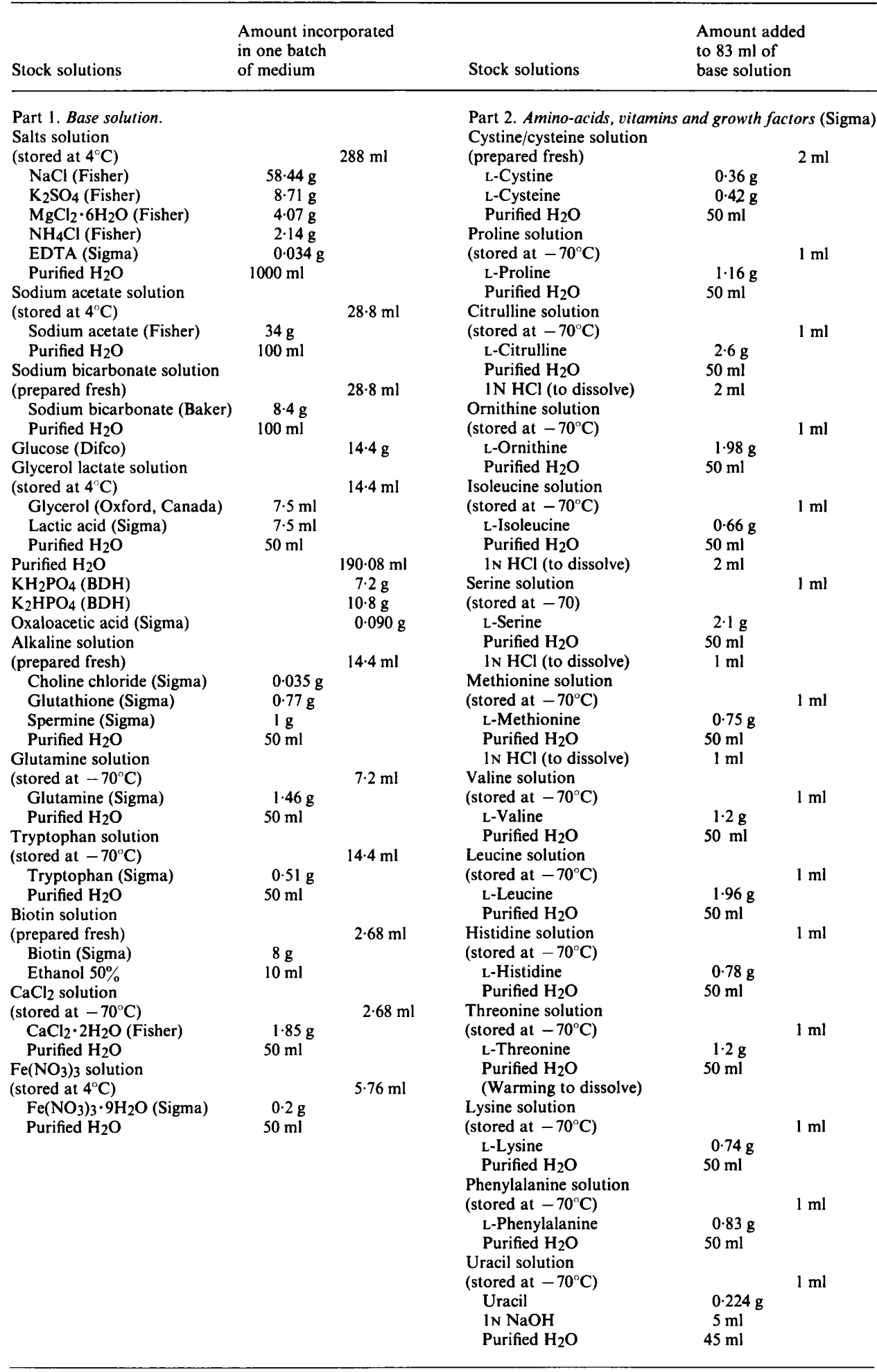




\begin{tabular}{|c|c|c|c|c|}
\hline TABLE I (contd) & & Stock solutions & $\begin{array}{l}\text { Amount addec } \\
\text { to } 83 \mathrm{ml} \text { of } \\
\text { base solution }\end{array}$ & \\
\hline $\begin{array}{l}\text { Part 3. Agar base. } \\
\text { Purified agar* } \\
\text { Purified } \mathrm{H}_{2} \mathrm{O}\end{array}$ & $\begin{array}{r}5 \cdot 2 \mathrm{~g} \\
300 \mathrm{ml}\end{array}$ & $\begin{array}{l}\text { Part } 2 \text { (contd) } \\
\text { Hypoxanthine solution } \\
\text { (stored at }-70^{\circ} \mathrm{C} \text { ) } \\
\text { Hypoxanthine } \\
\text { 1 N } \mathrm{NaOH} \\
\text { Purified } \mathrm{H}_{2} \mathrm{O} \\
\text { Vitamin solution } \\
\text { (prepared fresh) } \\
\text { NADH } \\
\text { Thiamine } \mathrm{HCl} \\
\text { Thiamine pyrophosphate } \\
\text { Calcium pantothenate } \\
\text { Inositol } \\
\text { Purified } \mathrm{H}_{2} \mathrm{O}\end{array}$ & $\begin{array}{c}0.136 \mathrm{~g} \\
5 \mathrm{ml} \\
45 \mathrm{ml} \\
\\
0.074 \mathrm{~g} \\
0.071 \mathrm{~g} \\
0.023 \mathrm{~g} \\
0.048 \mathrm{~g} \\
0.011 \mathrm{~g} \\
10 \mathrm{ml}\end{array}$ & $1 \mathrm{ml}$ \\
\hline
\end{tabular}

* To remove fatty acids, $100 \mathrm{~g}$ of Oxoid Agar No.1 were treated successively with $500 \mathrm{ml}$ of chloroform $(\mathrm{BDH}), 500 \mathrm{ml}$ of methanol (BDH), and $450 \mathrm{ml}$ of purified $\mathrm{H}_{2} \mathrm{O}$. The extracted agar was then dried before being weighed.

Purified $\mathrm{H}_{2} \mathrm{O}$ had been distilled once, de-ionised once, and passed through an organic adsorptive cartridge and a $0.45-\mu \mathrm{m}$ membrane filter (Millipore).

TABLE II

Relationship between auxotype and penicillinase production in 8599 isolates of N. gonorrhoeae

\begin{tabular}{|c|c|c|}
\hline \multirow[b]{2}{*}{ Auxotype } & \multicolumn{2}{|c|}{ Number $(\%)$ of isolates of } \\
\hline & PPNG & non-PPNG \\
\hline $\begin{array}{l}\text { Proto } \\
\text { Pro } \\
\text { Orn }^{-} \\
\text {Pro }^{-} \mathrm{Cit}^{-} \mathrm{Ura}^{-} \\
\text {Orn }^{-} \mathrm{Ura}^{-} \mathrm{Hyx}^{-} \\
\text {Cit }^{-} \mathrm{Ura}^{-} \mathrm{Hyx}^{-} \\
\text {Other } \\
\text { NG }\end{array}$ & $\begin{array}{rr}67 & (44) \\
78 & (51) \\
6 & (4) \\
0 & (0) \\
0 & (0) \\
0 & (0) \\
2 & (1) \\
0 & (0)\end{array}$ & $\begin{array}{rr}2590 & (31) \\
1136 & (13) \\
1026 & (12) \\
1699 & (20) \\
945 & (11) \\
215 & (3) \\
690 & (8) \\
145 & (2)\end{array}$ \\
\hline Total & $153(100)$ & $8446(100)$ \\
\hline
\end{tabular}

PPNG $=$ penicillinase-producing $N$. gonorrhoeae $;$ Proto $=$ prototrophic (not requiring any of the aminoacids when each was omitted singly from the defined medium); Pro $^{-}=$proline requiring; Orn $^{-}=$ornith ine requiring; $\mathrm{Pro}^{-} \mathrm{Cit}^{-} \mathrm{Ura}^{-}=$proline-citrulline-uracil requiring; $\mathrm{Orn}^{-} \mathrm{Ura}^{-} \mathrm{Hyx}^{-}=$ornithine-uracilhypoxanthine requiring; $\mathrm{Cit}^{-} \mathrm{Ura}^{-} \mathrm{Hyx}^{-}=$citrulline-uracil-hypoxanthine requiring; Other $=$cultures with nutritional requirements other than those listed above; $\mathbf{N G}=$ no growth on the complete auxotyping medium.

remaining $42 \%$ were susceptible to penicillin (MIC $\leq 0 \cdot 12 \mathrm{mg} / \mathrm{L}$ ), and had a wide range of nutritional requirements.

The isolates of non-PPNG from male and female patients had similar ranges of nutritional requirements (table IV) but the proportion of each auxotype was different for males and females. For example, prototrophes and proline-requiring strains were more frequent amongst the isolates from males ( $40 \%$ and $23 \%$, respectively) than from females $(22 \%$ and $9 \%)$. Conversely, proline-citrulline-uracil requiring strains, and ornithine-uracil-hypoxanthine requiring strains, were more frequent from females $(31 \%$ and $24 \%)$ than from males $(18 \%$ and $9 \%)$. 
TABLE III

Relationship between auxotype of $N$. gonorrhoeae and in vitro susceptibility to penicillin, for 8446 isolates of non-PPNG

\begin{tabular}{|c|c|c|c|}
\hline \multirow[b]{2}{*}{ Auxotype } & \multicolumn{3}{|c|}{$\begin{array}{c}\text { Number }(\%) \text { of isolates for which the MIC } \\
\text { of penicillin was }\end{array}$} \\
\hline & $\begin{array}{l}\leqslant 0 \cdot 12 \mathrm{mg} / \mathrm{L} \\
\text { (susceptible) }\end{array}$ & $\begin{array}{l}0.3 \mathrm{mg} / \mathrm{L} \\
\text { (moderately resistant) }\end{array}$ & $\begin{array}{l}\geqslant 0.6 \mathrm{mg} / \mathrm{L} \\
\text { (resistant) }\end{array}$ \\
\hline $\begin{array}{l}\text { Proto } \\
\text { Pro- } \\
\text { Orn }^{-} \\
\text {Pro }^{-} \mathrm{Cit}^{-} \mathrm{Ura}^{-} \\
\text {Orn }^{-} \mathrm{Ura}^{-} \mathrm{Hyx}^{-} \\
\mathrm{Cit}^{-} \mathrm{Ura}^{-} \mathrm{Hyx}^{-} \\
\text {Other } \\
\text { NG }\end{array}$ & $\begin{array}{l}398(5) \\
194(2) \\
965(11) \\
0(0) \\
945(11) \\
215(3) \\
648(8) \\
145(2)\end{array}$ & $\begin{aligned} 328 & (4) \\
41 & (0 \cdot 5) \\
61 & (0 \cdot 7) \\
1301 & (15) \\
0 & (0) \\
0 & (0) \\
25 & (0 \cdot 3) \\
0 & (0)\end{aligned}$ & $\begin{array}{c}1864(22) \\
901(11) \\
0(0) \\
398(5) \\
0(0) \\
0(0) \\
i 7(0 \cdot 2) \\
0(0)\end{array}$ \\
\hline Total & $3510(42)$ & $1756(21)$ & $3180(38)$ \\
\hline
\end{tabular}

For abbreviations, see footnote to table II.

TABLE IV

Relationship between auxotype of $N$. gonorrhoeae and patient's sex, for strains of non-PPNG isolated in 1980-1981

\begin{tabular}{l|cc}
\hline & \multicolumn{2}{|c}{$\begin{array}{c}\text { Number }(\%) \text { of isolates } \\
\text { from }\end{array}$} \\
\cline { 2 - 3 } Auxotype & $\begin{array}{c}\text { males } \\
(\mathrm{n}=1200)\end{array}$ & $\begin{array}{c}\text { females } \\
(\mathrm{n}=1200)\end{array}$ \\
\hline Proto & $474(40)$ & $262(22)$ \\
Pro $^{-}$ & $271(23)$ & $106(9)$ \\
Orn $^{-}$ & $99(8)$ & $106(9)$ \\
Pro $^{-} \mathrm{Cit}^{-} \mathrm{Ura}^{-}$ & $212(18)$ & $371(31)$ \\
Orn- $^{-}$Ura $^{-} \mathrm{Hyx}^{-}$ & $102(9)$ & $287(24)$ \\
$\mathrm{Cit}^{-}$Ura $^{-} \mathrm{Hyx}^{-}$ & $42(4)$ & $68(6)$ \\
\hline
\end{tabular}

For abbreviations, see footnote to table II.

\section{Discussion}

Of the 8599 cultures of $N$. gonorrhoeae tested in this study, 8454 required cystine or cysteine for growth, a finding consistent with that of Short et al. (1977). The remaining 145 failed to grow on the complete auxotyping medium and could not be evaluated for cystine and cysteine requirement.

Comparison between three Canadian studies of gonococcal auxotype-in Toronto (present study), in nearby Hamilton (Stewart and Hendry, 1979), and in more distant Montreal (Turgeon and Granger, 1980) — shows no obvious influence of geographical location. Prototrophes constituted $31 \%$ of non-PPNG isolates in Toronto (table II), only $13 \%$ in Hamilton, but $33 \%$ in Montreal. The proportions of auxotypes requiring ornithine-uracil-hypoxanthine and citrulline-uracil-hypoxanthine varied more widely: $14 \%$ in Toronto, $28 \%$ in Hamilton and $44 \%$ in Montreal. Isolates requiring only proline or ornithine accounted, respectively, for $13 \%$ and $12 \%$ in Toronto, $10 \%$ and $5 \%$ in Hamilton and $16 \%$ and $4 \%$ in Montreal. Strains requiring proline-citrulline-uracil 
formed $20 \%$ in Toronto and $39 \%$ in Hamilton, but were not mentioned in the Montreal study.

There are noticeable differences in the degree of penicillin resistance between the Toronto auxotypes (table III) and those reported from Hamilton. In Toronto, prototrophic and proline-requiring cultures showed a broad distribution of MICs, ranging from $\leqslant 0.12 \mathrm{mg} / \mathrm{L}$ to $\geqslant 0.6 \mathrm{mg} / \mathrm{L}$, whereas, in the Montreal study, the highest MICs were $0.08 \mathrm{mg} / \mathrm{L}$ for prototrophes and $0.32 \mathrm{mg} / \mathrm{L}$ for the proline-requiring strains. For ornithine-requiring cultures, the MICs of the Toronto isolates varied from $\leqslant 0.12 \mathrm{mg} / \mathrm{L}$ to $0.3 \mathrm{mg} / \mathrm{L}$, whereas the peak was $0.08 \mathrm{mg} / \mathrm{L}$ in the Hamilton study. For strains requiring proline-citrulline-uracil, in Toronto the MICs were $0.3-\geqslant 0.6 \mathrm{mg} / \mathrm{L}$, but in Hamilton they were much lower $(\geqslant 0.08 \mathrm{mg} / \mathrm{L})$. Therefore, the present results demonstrate a higher degree of penicillin resistance for all the auxotypes isolated in Toronto.

Although the PPNG cultures in the present study constituted only $2 \%$ of the 8599 isolates, they accounted for $23 \%$ of the total PPNG in Canada (Pauze and Dillon, 1982). Thus, along with $22 \%$ from other laboratories in Ontario, the Province of Ontario provided $45 \%$ of the Canadian total. Of the PPNG isolates in Toronto (table II), $44 \%$ were prototrophic, $51 \%$ proline-requiring, and $4 \%$ ornithine-requiring. Similar results were reported by Pauze and Dillon-50\% prototrophic, $49 \%$ prolinerequiring, and only $1 \%$ ornithine-requiring.

The co-operation and assistance of the staff of the N. gonorrhoeae and Media Laboratories is gratefully acknowledged.

\section{REFERENCES}

Carifo K, Catlin B W 1973 Neisseria gonorrhoeae auxotyping: Differentiation of clinical isolates based on growth responses on chemically defined media. Applied Microbiology 26:223-230.

Catlin B W 1973 Nutritional profiles of Neisseria gonorrhoeae, Neisseria meningitidis, and Neisseria lactamica in chemically defined media and the use of growth requirements for gonococcal typing. Journal of Infectious Diseases 128:178-194.

Hendry A T, Stewart I O 1979 Auxanographic grouping and typing of Neisseria gonorrhoeae. Canadian Journal of Microbiology 25:512-521.

Jorgensen J H, Lee J C, Alexander G A 1977 Rapid penicillinase paper strip test for detection of beta-lactamase-producing Haemophilus influenzae and Neisseria gonorrhoeae. Antimicrobial Agents and Chemotherapy 11:1087-1088.

Knapp J S, Holmes K K 1975 Disseminated gonococcal infections caused by Neisseria gonorrhoeae with unique nutritional requirements. Journal of Infectious Diseases 132:204-208.

Pauze M, Dillon J R 1982 Penicillinase-producing Neisseria gonorrhoeae in Canada: 1980-June 1982. Canada Diseases Weekly Report 8:141-143.

Short H B, Ploscowe V B, Weiss J A, Young F E 1977 Rapid method for auxotyping multiple strains of Neisseria gonorrhoeae. Journal of Clinical Microbiology 6:244-248.

Shtibel R 1975 A new improved medium for antibiotic susceptibility testing of $N$. gonorrhoeae. Health Laboratory Science 12:76-81.

Shtibel R 1982 Increased resistance of Neisseria gonorrhoeae to penicillin-Ontario. Canada Diseases Weekly Report 8:118-119.

Stewart I O, Hendry A T 1979 Association between the auxogroup of Neisseria gonorrhoeae and minimal inhibitory concentration of penicillin. Sexually Transmitted Diseases 6:247-252.

Thomson S E et al. 1978 Auxotypes and antibiotic susceptibility patterns of Neisseria gonorrhoeae from disseminated and local infections. Sexually Transmitted Diseases 5:127-131.

Turgeon P L, Granger M J 1980 Auxotypes of Neisseria gonorrhoeae isolated from localized and disseminated infections in Montreal. Canadian Medical Assocation Journal 123:381-384. 